\title{
Prognostic implications of mitral regurgitation in patients after cardiac resynchronization therapy
}

\section{Manlio Cipriani ${ }^{1 *}$, Maurizio Lunati ${ }^{1}$, Maurizio Landolina ${ }^{2}$, Alessandro Proclemer ${ }^{3}$, Giuseppe Boriani ${ }^{4,5}$, Renato P. Ricci ${ }^{6}$, Roberto Rordorf ${ }^{7}$, Maria Vittoria Matassini ${ }^{1,8}$, Luigi Padeletti9, Saverio lacopino ${ }^{10}$, Giulio Molon ${ }^{11}$, Giovanni B. Perego ${ }^{12}$ and Maurizio Gasparini ${ }^{13}$, on behalf of the Italian ClinicalService Project Investigators}

\footnotetext{
${ }^{1}$ Niguarda Ca' Granda Hospital, Milan, Italy; ${ }^{2}$ Ospedale Maggiore, Crema, Italy; ${ }^{3} \mathrm{~S}$. Maria della Misericordia Hospital, Udine, Italy; ${ }^{4}$ Institute of Cardiology, University of Bologna and Azienda Ospedaliera S, Orsola-Malpighi, Bologna, Italy; ${ }^{5}$ Cardiology Department, University of Modena and Reggio Emilia, Policlinico di Modena, Modena, Italy; ${ }^{6}$ San Filippo Neri Hospital, Rome, Italy; ${ }^{7}$ Fondazione Policlinico S. Matteo IRCCS, Pavia, Italy; ${ }^{8}$ Università Politecnica delle Marche, Ancona, Italy; ${ }^{9}$ Careggi Hospital, Firenze, Italy; ${ }^{10}$ GVM Care and Research, Città di Lecce Hospital, Lecce, Italy; ${ }^{11}$ Ospedale Sacro Cuore, Negrar, Italy; ${ }^{12}$ Istituto Auxologico Italiano, San Luca, Milan, Italy; and ${ }^{13}$ IRCCS Istituto Clinico Humanitas, Rozzano, Italy
}

Received 9 September 2015; revised 5 November 2015; accepted 19 January 2016; online publish-ahead-of-print 13 July 2016

Aim

Mitral regurgitation (MR) is a common finding in patients with heart failure with debatable effects on prognosis. Reduction in MR is one of the mechanisms by which cardiac resynchronization therapy (CRT) exerts its beneficial effects. We investigated the prognostic impact of baseline MR and MR persistence after CRT on outcomes of treated patients.

Methods We prospectively followed 1122 CRT patients $(66.4 \pm 10.3$ years, $78 \%$ male) who were stratified according to baseline and results MR severity as having MR- (degree $0-1 ; n=508,45 \%)$ or $M R+($ degrees $2-3-4 ; n=614,55 \%)$. In 916 patients (82\%) with MR severity data available at 1-year follow-up, the annual mortality rate was 3.4 and 6.0 per patient-year in the $M R-$ and $M R+$ group, respectively, with a 1 -year incidence rate ratio (IRR) of $1.76(P<0.001)$. Similar results were observed for cardiovascular mortality (1-year IRR 1.72, $P=0.002)$. When considering survival according to $M R$ severity after CRT, all-cause and cardiovascular mortality were lower in the improved than in the worsened group (1-year IRR 1.87 and 2.33, respectively; both $P<0.001$ ). Regression analysis showed that absence of MR improvement at follow-up was a significant independent predictor of both all-cause and cardiovascular mortality.

\section{Conclusions}

Baseline significant MR and absence of MR improvement after CRT are strongly predictive of less favourable long-term survival.

Keywords

Cardiac resynchronization therapy $\bullet$ Mitral regurgitation $\bullet$ Prognosis $\bullet$ Heart failure

\section{Introduction}

Functional mitral regurgitation (FMR) is a common finding in patients with heart failure (HF) reported in up to $35 \%$ of affected patients in its moderate to severe form. ${ }^{1,2}$ Left ventricular systolic dysfunction and dyssynchrony, changes in ventricular shape and size, and mitral annulus dilatation are responsible for the imbalance between closing and tethering forces that act on mitral valve competency, resulting in FMR. ${ }^{3}$ The effects of mitral regurgitation (MR) on prognosis have been hotly debated, but only controversial and inconclusive results are available ${ }^{1,4-8}$. Cardiac resynchronization therapy (CRT) is a recognized milestone in the treatment of advanced HF patients, and recently also for less severely affected patients, ${ }^{9,10}$ on top of optimal pharmacological therapy, and is

*Corresponding author. Dipartimento CardioToracoVascolare 'A. De Gasperis', Ospedale Niguarda Ca' Granda, Milano, Piazza Ospedale Maggiore 3-20162 Milan, Italy. Tel: +39026444 7791, Fax: +390264442566, Email: manlio.cipriani@ospedaleniguarda.it 
strongly supported by current guidelines ${ }^{11}$ because of the reduction in morbidity and mortality, ${ }^{12}$ and improvement of symptoms and quality of life of treated patients. ${ }^{13,14}$ In addition to these benefits, CRT has been shown to have favourable effects on FMR ${ }^{15}$ with both acute and late improvement. ${ }^{16}$ Persistence of FMR after CRT implantation and its relationship with clinical outcomes have been investigated in different studies showing contrasting effects of FMR on long-term survival. ${ }^{17-21}$ The aim of our research was to assess, in a large real-world cohort of patients treated with CRT, the impact of significant pre-implantation MR on mortality and to test the hypothesis that persistent MR after CRT is associated with unfavourable clinical outcomes.

\section{Methods}

\section{Patient population and project design}

Patients participating in the Italian ClinicalService Project (ClinicalTrials.gov Identifier: NCT01007474), a national medical care project aiming to improve the quality of diagnostic and therapeutic strategies using implantable cardiac devices in clinical practice, were considered for the present analysis. The project consists of a shared environment for the collection, management, analysis and reporting of data from patients in whom Medtronic devices have been implanted. An independent scientific committee of physicians prospectively identifies key clinical questions on a yearly basis for analysis and publication. A charter assigns the ownership of data to the centres and governs the conduct and relationship of the scientific committee and Medtronic. The project was approved by each site's Medical Ethics Committee or Medical Director and conforms to the principles outlined in the Declaration of Helsinki. Each patient provided informed consent for data collection and analysis.

For the present analysis, patients were included if information about $M R$ at baseline was available. Patients with mitral valve prolapse or flail, mitral valve repair or replacement before CRT implantation were excluded.

The research population included 1122 patients who had received a Medtronic CRT defibrillator (CRT-D) in accordance with implantable cardioverter defibrillator (ICD) and CRT guidelines ${ }^{22,23}$ [i.e. HF in New York Heart Association (NYHA) class II, III, or IV, depressed ventricular function (left ventricular ejection fraction, LVEF $\leq 35 \%$ ), and wide QRS complex $(\geq 120 \mathrm{~ms})]$.

\section{Echocardiographic examination and data collection at baseline}

At baseline the following data were collected: demographics and medical history, clinical examination, medical therapy, 12-lead electrocardiogram with interest focused on rhythm and QRS duration, NYHA functional class.

The baseline echocardiographic evaluation focused on measurements of standard left ventricular (LV) diameters and volumes, LVEF and assessment of mitral valve regurgitation. All echocardiographic measurements, including MR severity, were performed according to current and accepted European echocardiography guidelines. ${ }^{24,25}$ Baseline FMR severity was classified as absent (degree 0), mild (degree 1), moderate (degrees 2-3), or severe (degree 4).

Furthermore, the study population was divided into the following two groups: (i) patients without haemodynamically significant baseline
MR (degree $0-1, M R-$ ), and (ii) patients with haemodynamically significant baseline MR (degrees 2-3-4, MR+).

\section{Patient follow-up}

All patients were followed up according to each centre's clinical practice and on a regular basis according to the severity of symptoms and disease through standard in-hospital visits and phone interview.

Only patients with available information on MR degree at 1-year follow-up after CRT implantation were considered for the outcome analysis.

The variables collected at follow-up included medical history, clinical examination, medical therapy, 12-lead electrocardiogram with interest focused on rhythm and QRS duration, NYHA functional class, echocardiographic parameters (LVEF, LV volumes and diameters, and presence and severity of MR), and death.

Patients were considered echocardiographic CRT-responders (echo-responders) if at least one of the following conditions were verified: ${ }^{26}$ (i) at least $10 \%$ relative reduction in $L V$ end-systolic volume (LVESV); (ii) at least $10 \%$ absolute increase in LVEF.

Based on the 1-year echocardiographic evaluation, patients were further classified as 'improved' or MR - 'unchanged' if they improved by at least one MR degree or remained unchanged with respect to baseline MR degree 0-1; or 'worsened' or MR+ 'unchanged' if they worsened by at least one $M R$ degree or remained unchanged with respect to baseline MR degrees 2-3-4.

The main outcome variable was death, classified as cardiovascular or non-cardiovascular.

\section{Endpoints}

Mortality data were collected from medical records, or through interviews with patients' caregiver(s) or family physicians, as appropriate. An independent scientific committee of physicians periodically reviewed the hard endpoint, including mortality and hospitalization, and validated the events according to the information reported.

The primary endpoint of this analysis was to assess mortality according to MR severity during long-term follow-up after CRT implantation. We also aimed to define predictors of death and worsening of MR severity in patients after CRT.

\section{Statistical analysis}

Descriptive statistics are reported as means and standard deviations for normally distributed continuous variables, or medians with 25 th -75 th interquartile range (IQR) for skewed distribution, while categorical variables are expressed as absolute and relative frequencies. All-cause and cardiovascular mortality were assessed using the Kaplan-Meier method. Comparison between groups for Kaplan-Meier analyses was made using the log rank test. Predictors of all-cause and cardiovascular mortality were estimated by computing hazard ratios (HR) and $95 \%$ confidence intervals $(\mathrm{Cl})$ by means of the Cox regression method. After checking for collinearity and proportionality, all variables associated with a $P$-value $<0.05$ on univariate analysis were entered into the multivariate Cox model. Predictors of worsening MR were evaluated by univariate and multivariate logistic regression. All variables associated with a $P$-value $<0.05$ on univariate analysis were entered into the multivariate model. For all analyses, a $P$-value $<0.05$ was considered statistically significant. Statistical analysis was performed using STATA 12.1 (StataCorp LP, College Station, TX, USA). 


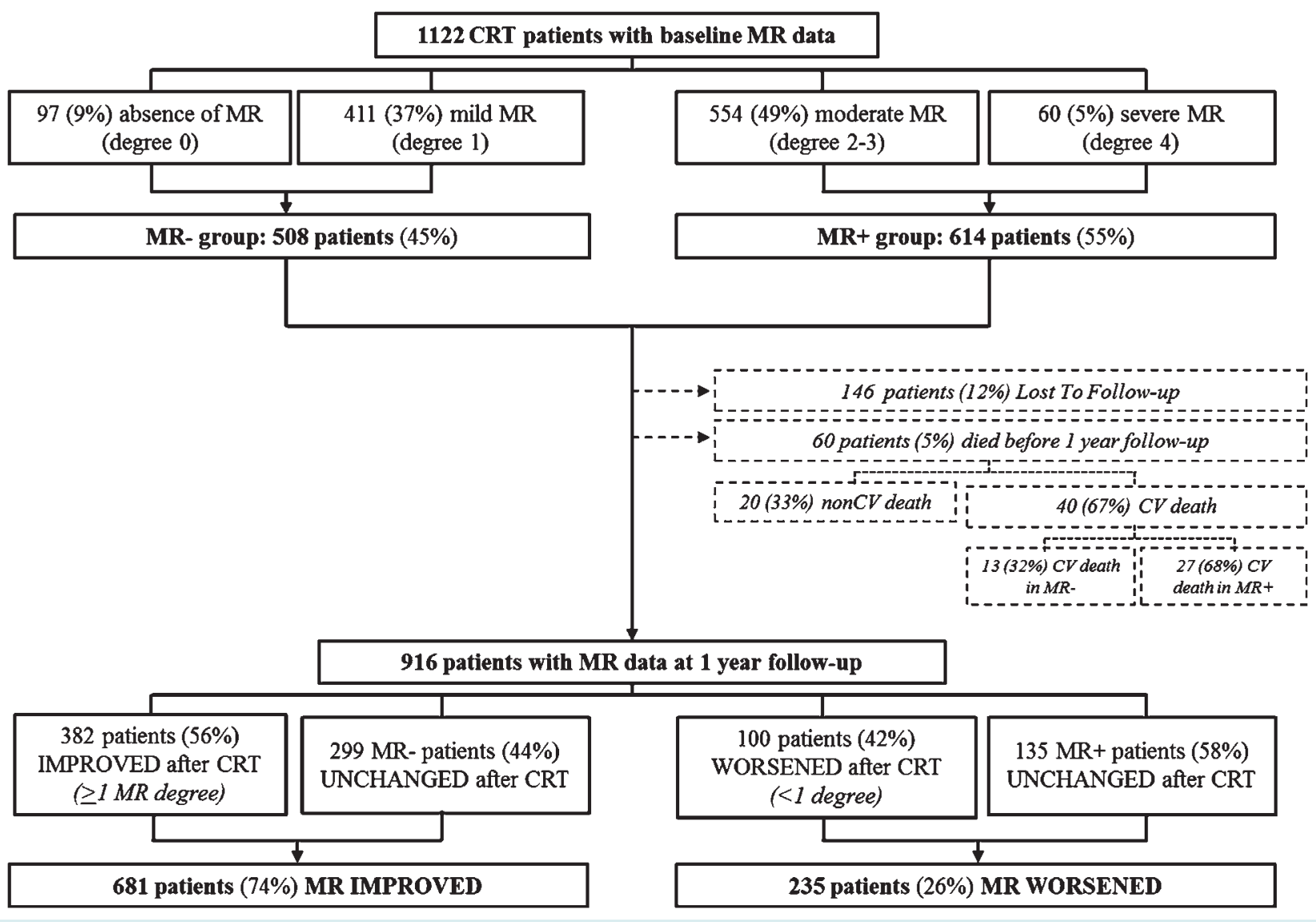

Figure 1 Flow-chart of patients from the Italian ClinicalService Project implanted with cardiac resynchronization therapy (CRT) who were considered in the analysis. The prevalence of mitral regurgitation (MR) before and after CRT is shown. Sixty patients died before the 1-year follow-up. CV, cardiovascular; MR-, patients without haemodynamically significant baseline MR (degrees 0-1); MR+, patients with haemodynamically significant baseline MR (degrees 2-3-4).

\section{Results}

The overall population included 1122 patients implanted with CRT who underwent baseline echocardiographic assessment of MR, but only patients with MR evaluated at 1-year follow-up were considered for primary endpoint analysis. A total of 916 patients were retrieved, because: 146 patients (13\%) were lost to follow-up and 60 patients $(5 \%)$ died before 1-year follow-up after CRT implantation. The flow-chart regarding patient inclusion is drawn in Figure 1.

As shown in Figure 2, 508 patients (45\%) had nonhaemodynamically significant $M R$ (MR-: degree $0-1)$, whereas 614 patients $(55 \%)$ had at least moderate $M R(M R+$ : degrees 2-3-4) at baseline.

Baseline characteristics of the overall study population with MR severity at CRT implant are reported in Table 1. Clinical variables were comparable between groups, except that patients with significant MR were older, received more frequently diuretics and presented a significantly wider QRS duration and a higher percentage of left bundle branch block.
Moreover, as regards echocardiographic parameters, patients with haemodynamically significant MR showed lower LVEF and higher LV volumes (Table 1).

\section{Follow-up assessment after cardiac resynchronization therapy}

A total of 494 patients (57.2\%) were echo-responders to CRT, without any difference after dividing the population according to pre-implant severity of $M R(58.7 \%$ in $M R-$ and $55.9 \%$ in $M R+$, $P=0.410)$.

Based on MR degree at follow-up, 681 patients (74\%) had improved and 235 (26\%) had worsened. In the improved group, MR decreased by at least 1 degree from baseline in 382 patients (56\%) and remained unchanged in 299 (44\%); conversely, MR worsened in 100 patients $(42 \%)$ or remained equal to or more than moderate in 135 patients (57\%) (Figure 2).

On the whole, baseline characteristics were comparable between improved and worsened patients, except for a higher frequency of ischaemic cardiomyopathy, a higher dose of diuretics, 


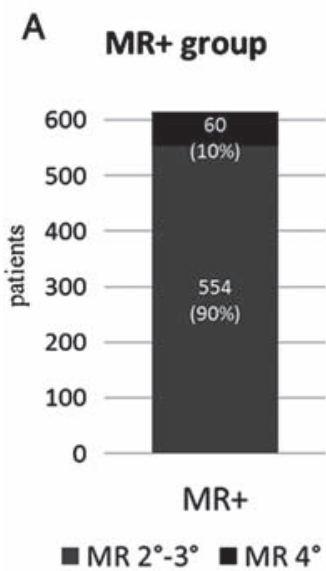

B

\section{MR WORSENED}

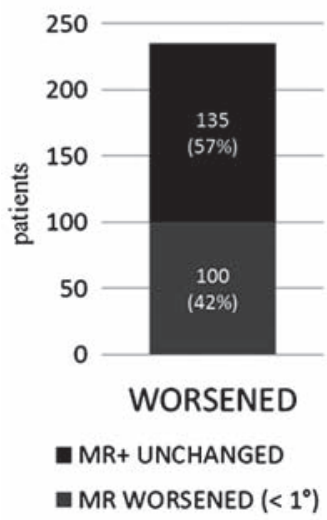

\section{Baseline MR Distribution}

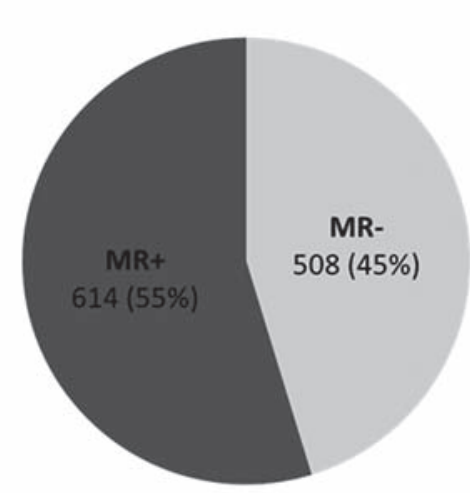

MR Distribution at Follow-up

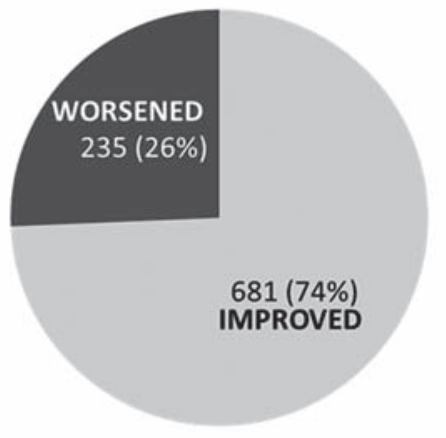

\section{MR-group}

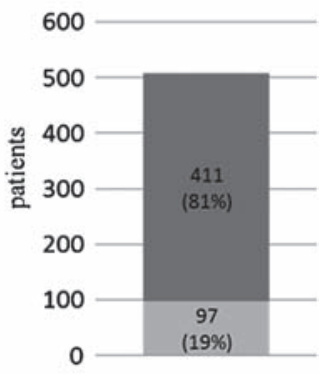

MR-

$M \mathrm{MR} 0^{\circ}=\mathrm{MR} 1^{\circ}$

\section{MR IMPROVED}

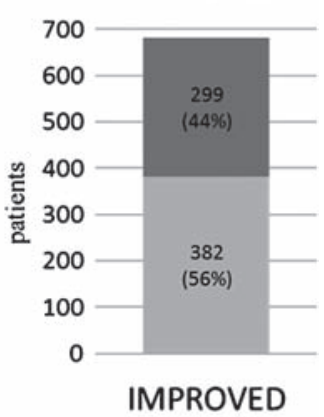

- MR- UNCHANGED

$=$ MR IMPROVED $\left(21^{\circ}\right)$

Figure 2 Distribution of mitral regurgitation (MR) at baseline (a) and after 1 year of cardiac resynchronization therapy (CRT) (b). MR-, patients without haemodynamically significant baseline $M R$ (degree $0-1$ ); $M R+$, patients with haemodynamically significant baseline $M R$ (degrees $2-3-4)$.

a higher prevalence of permanent atrial fibrillation (AF), and more dilated ventricles in the second group (Table 1).

Echocardiographic response to CRT was significantly lower in the worsened group than in the improved group $(41.8 \%$ vs. $62.3 \%$, $P<0.001)$.

\section{Impact of mitral regurgitation severity on patient outcomes}

During a median follow-up of 38.6 months (1st-3rd quartile 21.1-65.6 months), a total of 205 patients (18\%) reached the primary endpoint of the analysis, with 69 deaths $(13.6 \%)$ in the MRgroup and 136 deaths $(22.2 \%)$ in the MR+ group. The annual mortality rate (per 100 person/year) in the MR - group was $3.4(95 \% \mathrm{Cl}$ $2.7-4.3)$ vs. $6.0(95 \% \mathrm{Cl} 5.0-7.1)$ in the $\mathrm{MR}+$ group, with an annual incidence rate ratio (IRR) of $1.76(95 \% \mathrm{Cl} 1.31-2.39, P<0.001)$.
The Kaplan-Meier survival curves of the study population according to baseline severity of $M R$ are shown in Figure $3 a$. Cardiovascular mortality was significantly higher in patients with at least moderate MR than in patients with no or mild MR [94 (15.3\%) vs. 49 cardiovascular deaths (9.7\%)], with an annual IRR of $1.72(95 \% \mathrm{Cl} 1.10-2.57, P=0.002)$ (Figure 3b).

The assessment of survival according to MR severity after CRT revealed that patients of the worsened group had a less favourable outcome than patients of the improved group (Figure 3c). Accordingly, the annual mortality rate (per 100 person/year) in the improved group was significantly lower than that of the worsened group [3.1 (95\% Cl 2.5-3.7) vs. $5.7(95 \% \mathrm{Cl} 4.3-7.5)]$, with an annual IRR of 1.87 ( $95 \% \mathrm{Cl} 1.21-2.66, P<0.001)$.

Deaths for cardiovascular reasons were significantly higher in the worsened group compared with the improved group, respectively [53 deaths (7.8\%) vs. 38 deaths (16.2\%)], giving an annual IRR of 
Table 1 Characteristics of the study population according to baseline severity of mitral regurgitation (MR) and to MR severity at follow-up after cardiac resynchronization therapy (CRT)

\begin{tabular}{|c|c|c|c|c|c|c|c|}
\hline & $\begin{array}{l}\text { Total population } \\
(n=1122)\end{array}$ & $\begin{array}{l}\text { MR- } \\
(n=508)\end{array}$ & $\begin{array}{l}\text { MR+ } \\
(n=614)\end{array}$ & $P$-value & $\begin{array}{l}\text { MR improved } \\
(n=681)\end{array}$ & $\begin{array}{l}\text { MR worsened } \\
(n=235)\end{array}$ & $P$-value \\
\hline Age (years) & $66.4 \pm 10.3$ & $65.3 \pm 10.5$ & $67.4 \pm 10.0$ & 0.001 & $65.8 \pm 10.4$ & $66.6 \pm 9.4$ & 0.498 \\
\hline Male gender & 875 (78.0\%) & $406(80.0 \%)$ & 469 (76.4\%) & 0.147 & 527 (77.4\%) & $184(78.2 \%)$ & 0.800 \\
\hline NYHA class III/IV & $806(71.8 \%)$ & $355(69.8 \%)$ & 451 (73.5\%) & 0.170 & $484(71.0 \%)$ & 165 (70.4\%) & 0.862 \\
\hline Ischaemic heart disease & $527(47.0 \%)$ & $239(47.0 \%)$ & $288(46.9 \%)$ & 0.973 & $298(43.7 \%)$ & $120(51.1 \%)$ & 0.050 \\
\hline Chronic AF & $356(31.7 \%)$ & $156(30.8 \%)$ & $200(32.5 \%)$ & 0.543 & $195(28.7 \%)$ & 84 (35.7\%) & 0.045 \\
\hline QRS (ms) & $152.9 \pm 27.1$ & $149.0 \pm 28.7$ & $156.2 \pm 25.4$ & $<0.001$ & $154.1 \pm 28.6$ & $153.4 \pm 28.9$ & 0.574 \\
\hline QRS $>150 \mathrm{~ms}$ & $600(53.4 \%)$ & $259(51.0 \%)$ & 341 (55.7\%) & 0.116 & $389(57.1 \%)$ & $123(52.3 \%)$ & 0.201 \\
\hline CRT-D & 933 (83.2\%) & 429 (84.5\%) & $504(82.1 \%)$ & 0.298 & 537 (78.9\%) & $190(80.9 \%)$ & 0.575 \\
\hline LBBB & $774(69.0 \%)$ & $314(61.9 \%)$ & $460(75.0 \%)$ & $<0.001$ & $471(69.1 \%)$ & $169(71.9 \%)$ & 0.420 \\
\hline LVEF (\%) & $27.8 \pm 6.6$ & $28.9 \pm 6.0$ & $27.0 \pm 7.0$ & $<0.001$ & $28.2 \pm 6.9$ & $27.8 \pm 6.2$ & 0.686 \\
\hline LVEDV (mL) & $209.2 \pm 70.3$ & $197.7 \pm 65.9$ & $218.7 \pm 72.4$ & $<0.001$ & $208.0 \pm 69.9$ & $216.2 \pm 76.4$ & 0.284 \\
\hline LVESV (mL) & $154.1 \pm 55.2$ & $144.4 \pm 51.9$ & $162.2 \pm 56.6$ & $<0.001$ & $152.6 \pm 54.6$ & $161.0 \pm 63.7$ & 0.043 \\
\hline LVEDV index $\left(\mathrm{mL} / \mathrm{m}^{2}\right)$ & $113.4 \pm 33.7$ & $103.9 \pm 26.4$ & $121.2 \pm 36.9$ & $<0.001$ & $111.7 \pm 29.2$ & $115.6 \pm 27.9$ & 0.018 \\
\hline LVESV index $\left(\mathrm{mL} / \mathrm{m}^{2}\right)$ & $85.0 \pm 27.3$ & $77.2 \pm 20.8$ & $91.4 \pm 30.2$ & $<0.001$ & $83.7 \pm 22.9$ & $86.4 \pm 23.1$ & 0.004 \\
\hline \multicolumn{8}{|l|}{ Drug therapy } \\
\hline Diuretics & $1013(90.3 \%)$ & $448(88.1 \%)$ & $565(92.1 \%)$ & 0.024 & 599 (88.0\%) & $223(95.1 \%)$ & 0.002 \\
\hline Beta-blockers & $865(77.1 \%)$ & 393 (77.4\%) & 472 (76.9\%) & 0.843 & $550(80.8 \%)$ & $181(77.2 \%)$ & 0.235 \\
\hline ACE-I/ARB & 924 (82.4\%) & $428(84.3 \%)$ & 496 (80.8\%) & 0.126 & $599(88.0 \%)$ & $203(86.4 \%)$ & 0.521 \\
\hline
\end{tabular}

AF, atrial fibrillation; ACE-I, angiotensin-converting enzyme inhibitors; ARB, angiotensin receptor blockers; CRT-D, cardiac resynchronization therapy with defibrillator; LBBB, left bundle branch block; LVEF, left ventricular ejection fraction; LVESV, left ventricular end-systolic volume; LVEDV, left ventricular end-diastolic volume; MR-, patients without haemodynamically significant baseline MR (degree 0-1); MR+, patients with haemodynamically significant baseline MR (degrees 2-3-4); NYHA, New York Heart Association.

$2.33(1.50-3.60, P<0.001)$. The $C V$ survival curves are provided in Figure $3 d$.

\section{Predictors of death and improvement in mitral regurgitation}

Univariate Cox analysis (Table 2) revealed that absence of MR improvement after CRT, advanced age, NYHA class IV, chronic AF, and ischaemic cardiomyopathy aetiology were predictive factors of both all-cause and cardiovascular mortality. Using a multivariate model, the following factors were independently associated with all-cause mortality: advanced age, NYHA class IV, chronic AF, and ischaemic cardiomyopathy (Table 2). Both NYHA class IV and AF were also predictors of cardiovascular mortality. The absence of MR improvement after CRT was an independent strong predictor for both all-cause mortality $(\mathrm{HR} 1.58, P=0.015)$ and cardiovascular death (HR 2.13, $P=0.001$ ) (Table 2).

Considering MR severity after CRT, logistic univariate analysis showed that the presence of at least moderate MR at baseline and chronic AF had a positive correlation with worsening MR, while LVEF had a weak association with improvement in MR severity after CRT (Table 3). The same factors were independently associated with worsening MR after CRT at multivariable analysis (Table 3).

\section{Discussion}

The prognostic impact of MR on chronic HF has been debated with equivocal results. Several authors reported a reduced survival in all
HF patients, 1,5,8,27 whereas others found either a reduced survival only for less advanced stages of LV dysfunction ${ }^{6}$ or no correlation between MR and mortality. ${ }^{4}$ However, MR also correlates with severity of symptoms and quality of life, and untreated MR in HF patients is a determinant of frequent hospital readmissions. ${ }^{28}$

Cardiac resynchronization therapy has been shown to reduce MR by $30-40 \%,{ }^{29}$ through early ${ }^{30,31}$ and delayed effects. ${ }^{17}$ The first acting mechanism is resynchronization per se in terms of synchronized contraction of the papillary muscles; ${ }^{30,31}$ later, ventricular remodelling with secondary effects on mitral valve geometry are involved in the reduction of MR. ${ }^{16,17}$ For these reasons, there is an increasing interest in considering CRT as a treatment option in patients with significant MR and advanced HF.

Our analysis reveals that baseline significant $M R$ and absence of improvement in MR after 1 year of CRT are important predictors of unfavourable long-term survival. In our population, $74 \%$ of patients derived benefit from CRT because MR improved or did not change toward significant haemodynamic MR during the follow-up. Similar results were found by Onishi et al. ${ }^{18}$ while in other studies the percentage improvement in MR was lower, ${ }^{21,32-34}$ likely because of the different methods used to classify the reduction in MR or the different durations of follow up.

In $26 \%$ of the cohort, however, significant MR was still present at follow-up and this result carried a strong prognostic value. Indeed, the main message of our research is that MR persistence or worsening after CRT implantation identified a subgroup of patients with a worse prognosis. We found that patients with persistent significant MR had a lower echocardiographic response to CRT 

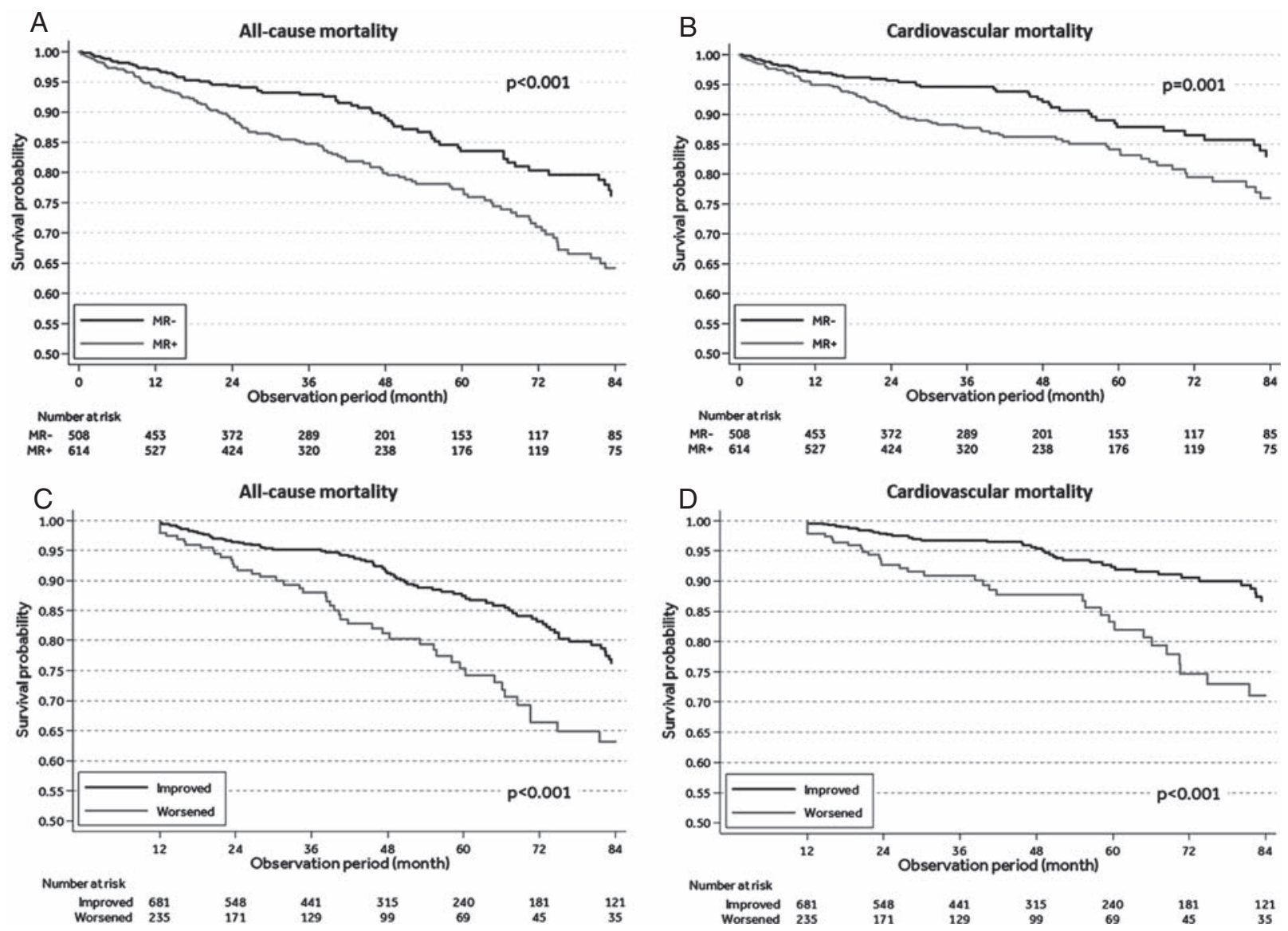

Figure 3 Kaplan-Meier curves for all-cause (a) and cardiovascular mortality (b) according to baseline mitral regurgitation (MR) severity, and Kaplan-Meier curves for all-cause (c) and cardiovascular mortality (d) according to improvement in MR at follow-up. Curves have been cut, graphically, at 84 months because after that time the patients at risk in each group were less than $15 \%$ of the initial population.

(41.8\% vs. $62.3 \%, P<0.001)$ associated with a worse survival compared with patients with mild/absent or improved MR after electrical therapy. Moreover, the absence of improvement in MR after CRT was an independent predictor of both all-cause and cardiovascular mortality at univariate analysis, and of cardiovascular mortality at multivariate analysis, underlining once again the strong impact of this finding on HF patient outcomes.

Persistence of MR after biventricular stimulation has been related to low echocardiographic response to CRT in the long term $^{32}$ and to increased mortality. ${ }^{18,20,33,35}$ In our research, patients with persistent MR after CRT showed a significantly lower echocardiographic response to CRT and a higher mortality rate. In daily clinical practice, the evidence of significant persistent mitral valve insufficiency, despite optimal medical therapy and CRT, highlights the need for early consideration for alternative MR treatment with the aim of improving clinical response and outcomes. At present, several therapeutic options are available. The surgical approach is possible; however, there are some concerns about its effects on long term survival and its safety in patients with advanced HF, generally considered at high perioperative risk and often excluded from this strategy. ${ }^{28}$ Recently, percutaneous techniques have been assessed with preliminary but encouraging results.

We also characterized patients who presented with improvement in MR. They showed less dilated ventricles at baseline. As already reported in the literature, ${ }^{18,32}$ excessive ventricular dilatation is associated with reduced benefit from CRT in terms of global response and mitral valve function. Moreover, the ischaemic aetiology was more frequent in patients with worsening MR after CRT. This observation is consistent with previous findings ${ }^{18,33}$ and may result from the presence of scarring at the site of the papillary muscles or from progressive regional loss of viable myocardium due to ischaemia, both of which may limit the action of resynchronization. ${ }^{15,29}$

However, neither LV dimensions nor aetiology were found to be independently associated with improvement in MR at univariate or multivariate analysis.

The only feature predictive of a reduction in MR in our population was baseline presence of MR per se. Mitral regurgitation of moderate degree before CRT has been considered a positive finding predicting good echocardiographic response to biventricular stimulation therapy, whereas severe MR has been shown to limit 
Table 2 Predictive factors of all-cause and cardiovascular mortality at follow-up by Cox regression analysis

\begin{tabular}{|c|c|c|c|c|c|c|}
\hline & \multicolumn{3}{|c|}{ All-cause mortality } & \multicolumn{3}{|c|}{ Cardiovascular mortality } \\
\hline & $P$-value & HR & $95 \% \mathrm{Cl}$ & $P$-value & HR & $95 \% \mathrm{Cl}$ \\
\hline \multicolumn{7}{|l|}{ Univariate } \\
\hline Baseline MR (MR+) & $<0.001$ & 1.80 & $1.34-2.40$ & 0.002 & 1.75 & $1.24-2.47$ \\
\hline Absence of improvement in MR & $<0.001$ & 1.79 & $1.34-2.40$ & $<0.001$ & 2.39 & $1.58-3.63$ \\
\hline Sex (male) & 0.230 & 1.24 & $0.87-1.76$ & 0.422 & 1.18 & $0.78-1.79$ \\
\hline Age (10 units-years) & $<0.001$ & 1.03 & $1.02-1.05$ & 0.002 & 1.03 & $1.01-1.05$ \\
\hline NYHA class IV & 0.003 & 1.99 & $1.26-3.13$ & 0.001 & 2.43 & $1.46-4.03$ \\
\hline Chronic AF & 0.001 & 1.63 & $1.22-2.19$ & 0.001 & 1.82 & $1.29-2.58$ \\
\hline Ischaemic cardiomyopathy & $<0.001$ & 1.77 & $1.34-2.33$ & 0.015 & 1.61 & $1.51-1.08$ \\
\hline QRS (1 unit-ms) & 0.939 & 1.00 & $0.99-1.01$ & 0.603 & 1.00 & $1.00-1.01$ \\
\hline CRT-D & 0.017 & 1.53 & $1.08-2.16$ & 0.062 & 1.49 & $0.98-2.27$ \\
\hline \multicolumn{7}{|l|}{ Multivariate } \\
\hline Baseline MR (MR+) & 0.041 & 1.47 & $1.02-2.12$ & 0.127 & 1.46 & $0.90-2.36$ \\
\hline Absence of improvement in MR & 0.015 & 1.58 & $1.09-2.28$ & 0.001 & 2.13 & $1.35-3.39$ \\
\hline Age (10 units-years) & 0.010 & 1.03 & $1.01-1.05$ & 0.104 & 1.02 & $1.00-1.05$ \\
\hline NYHA class IV & 0.032 & 1.80 & $1.05-3.07$ & 0.045 & 1.96 & $1.02-3.77$ \\
\hline Chronic AF & 0.035 & 1.48 & $1.03-2.14$ & 0.062 & 1.57 & $0.98-2.51$ \\
\hline LVEF (\%, -1 unit) & - & - & - & 0.249 & 0.98 & $0.94-1.02$ \\
\hline Ischaemic cardiomyopathy & 0.015 & 1.59 & $1.09-2.31$ & 0.245 & 1.31 & $0.83-2.06$ \\
\hline CRT-D & 0.513 & 1.15 & $0.75-1.77$ & - & - & - \\
\hline
\end{tabular}

AF, atrial fibrillation; $\mathrm{Cl}$, confidence interval; HR, hazard ratio; CRT-D, cardiac resynchronization therapy with defibrillator; LVEF, left ventricular ejection fraction; MR, mitral regurgitation; MR+, patients with haemodynamically significant baseline MR (degrees 2-3-4); NYHA, New York Heart Association.

Table 3 Predictors of mitral regurgitation worsening after cardiac resynchronization therapy at univariate and multivariate logistic analysis

\begin{tabular}{|c|c|c|c|}
\hline & $P$-value & HR & $95 \% \mathrm{Cl}$ \\
\hline \multicolumn{4}{|l|}{ Univariate } \\
\hline Baseline MR (MR+) & $<0.001$ & 2.03 & $1.49-2.76$ \\
\hline Sex (male) & 0.788 & 1.05 & $0.73-1.50$ \\
\hline Age (10 units-years) & 0.421 & 1.01 & $0.99-1.02$ \\
\hline NYHA class IV & 0.287 & 1.43 & $0.74-2.75$ \\
\hline Chronic AF & 0.050 & 1.38 & $1.00-1.91$ \\
\hline LVEF (\%, 10 units) & $<0.001$ & 0.95 & $0.94-0.97$ \\
\hline Ischaemic cardiomyopathy & 0.053 & 1.34 & $1.00-1.81$ \\
\hline QRS (ms, 1 unit) & 0.727 & 1.00 & $0.99-1.00$ \\
\hline CRT-D & 0.515 & 1.13 & $0.78-1.64$ \\
\hline \multicolumn{4}{|l|}{ Multivariate } \\
\hline Baseline MR (MR+) & $<0.001$ & 1.90 & $1.37-2.63$ \\
\hline Chronic AF & 0.046 & 1.41 & $1.01-1.98$ \\
\hline LVEF (\%, 10 units) & $<0.001$ & 0.95 & $0.94-0.97$ \\
\hline
\end{tabular}

$A F$, atrial fibrillation; $\mathrm{Cl}$, confidence interval; $\mathrm{HR}$, hazard ratio; CRT-D, cardiac resynchronization therapy with defibrillator; LVEF, left ventricular ejection fraction; MR, mitral regurgitation; MR+, patients with haemodynamically significant baseline MR (degrees 2-3-4); NYHA, New York Heart Association.

CRT-related reverse remodelling. ${ }^{19,36}$ Therefore, the maximum benefit of CRT on FMR and LV remodelling should be observed in those patients with at least mild MR, not reaching a severe degree, that may represent a too late and perhaps irreversible stage of LV dysfunction and dilatation to receive benefit from electrical therapy.

\section{Limitations}

The first limitation of our study lies in its observational nature and potential bias in patient selection and treatment, and device programming, because of the lack of a control group of patients not implanted with CRT. However, this limitation may be tempered by the fact that data were collected prospectively, the analysis was designed before the dataset was opened, and research endpoints were pre-specified. The second limitation, which may arise from the analysis of the results, is the relatively low frequency of the primary endpoint expressed as annual mortality rate, when compared with previous survival data in advanced $\mathrm{HF}$ populations. However, our results reflect real-word clinical practice where specialists with expertise in dedicated clinics tightly follow patients with advanced HF and may have optimized therapy and subsequent management on a case-by-case basis, with a favorable impact on prognosis.

Finally, echocardiographic assessment was not evaluated by a core laboratory. However, the fact that (i) a large sample was included in the analysis, (ii) only experienced echocardiographers performed all the studies, grounding their evaluation on recognized guidelines, and (iii) the cohort was divided into a haemodynamically significant group (MR degrees 2-3-4) vs. a non-haemodynamically significant group ( $M R$ degree $0-1$ ), are all factors that could have contributed to reduce the bias of not having a central core laboratory. 


\section{Conclusions}

Cardiac resynchronization therapy reduces MR severity in patients with advanced HF, though no improvement is detected in one third of cases. Persistence of significant MR after CRT is associated with lower echocardiographic response to CRT and is strongly predictive of less favourable long-term survival. This prognostic effect of MR poses the need to consider alternative options for $\mathrm{HF}$ patients with persistent haemodynamically significant $M R$.

\section{Acknowledgements}

Authors thank Silvia Bisetti for her scientific advice to this research project and Claudia Campo for contributing to statistical analysis.

\section{Funding}

This research was performed within the framework of the Italian ClinicalService, a project funded by Medtronic Italia, an affiliate of Medtronic Inc. No other funding sources were involved in the research.

Conflict of interest: M.L. has received modest consultancy and speaker's fees from Medtronic, St Jude Medical, Sorin, Boston Scientific, and Biotronik. M.L. has received modest speaker fees from, and has an advisory board relationship with Medtronic and St Jude Medical. G.B. has received minor consultancy fees from Boston Scientific and Medtronic. R.P.R. has received minor consultancy fees from Biotronik and Medtronic. R.R. has received speaking fees from Medtronic and St Jude Medical. G.M. has served as consultant for Boston and Medtronic and has served as investigator for Boston Scientific, Medtronic, St Jude Medical, and Sorin. G.B.P. received consultancy fees from Medtronic. The other authors have no conflicts to disclose with regard to the present research.

\section{References}

1. Trichon BH, Felker GM, Shaw LK, Cabell CH, O'Connor CM. Relation of frequency and severity of mitral regurgitation to survival among patients with left ventricular systolic dysfunction and heart failure. Am / Cardiol 2003;91:538-543.

2. Robbins JD, Maniar PB, Cotts W, Parker MA, Bonow RO, Gheorghiade M. Prevalence and severity of mitral regurgitation in chronic systolic heart failure. Am J Cardiol 2003;91:360-362.

3. Punnoose L, Burkhoff D, Cunningham L, Horn EM. Functional mitral regurgitation: therapeutic strategies for a ventricular disease. J Card Fail 2014;20:252-267.

4. Patel JB, Borgeson DD, Barnes ME, Rihal CS, Daly RC, Redfield MM. Mitral regurgitation in patients with advanced systolic heart failure. J Card Fail 2004;10:285-291.

5. Koelling TM, Aaronson KD, Cody RJ, Bach DS, Armstrong WF. Prognostic significance of mitral regurgitation and tricuspid regurgitation in patients with left ventricular systolic dysfunction. Am Heart J 2002;144:524-529.

6. Bursi F, Barbieri A, Grigioni F, Reggianini L, Zanasi V, Leuzzi C, Ricci C, Piovaccari G, Branzi A, Modena MG. Prognostic implications of functional mitral regurgitation according to the severity of the underlying chronic heart failure: a long-term outcome study. Eur J Heart Fail 2010;12:382-388.

7. Lancellotti P, Gérard PL, Piérard LA. Long-term outcome of patients with heart failure and dynamic functional mitral regurgitation. Eur Heart $J$ 2005;26:1528-1532.

8. Baskett RJF, Exner D V, Hirsch GM, Ghali WA. Mitral insufficiency and morbidity and mortality in left ventricular dysfunction. Can J Cardiol 2007;23:797-800.

9. Hai OY, Mentz RJ, Zannad F, Gasparini M, De Ferrari GM, Daubert JC, Holzmeister J, Lam CS, Pochet T, Vincent A, Linde C. Cardiac resynchronization therapy in heart failure patients with less severe left ventricular dysfunction. Eur J Heart Fail 2015;17:135-143.
10. Herscovici R, Kutyifa V, Barsheshet A, Solomon S, McNitt S, Polonsky B, Lee AY, Zareba W, Moss AJ, Goldenberg I. Early intervention and long-term outcome with cardiac resynchronization therapy in patients without a history of advanced heart failure symptoms. Eur J Heart Fail 2015;17:964-970.

11. McMurray JJ, Adamopoulos S, Anker SD, Auricchio A, Böhm M, Dickstein K, Falk V, Filippatos G, Fonseca C, Gomez-Sanchez MA, Jaarsma T, Køber L, Lip GY, Maggioni AP, Parkhomenko A, Pieske BM, Popescu BA, Rønnevik PK, Rutten FH, Schwitter J, Seferovic P, Stepinska J, Trindade PT, Voors AA, Zannad $F$, Zeiher A. ESC Guidelines for the diagnosis and treatment of acute and chronic heart failure 2012: the Task Force for the Diagnosis and Treatment of Acute and Chronic Heart Failure 2012 of the European Society of Cardiology. Developed in collaboration with the Heart Failure Association (HFA). Eur J Heart Fail 2012;14:803-869.

12. Gasparini M, Klersy C, Leclercq C, Lunati M, Landolina M, Auricchio A, Santini M, Boriani G, Proclemer A, Leyva F. Validation of a simple risk stratification tool for patients implanted with cardiac resynchronization therapy: the VALID-CRT risk score. Eur J Heart Fail 2015;17:717-724.

13. Linde C, Leclercq C, Rex S, Garrigue S, Lavergne T, Cazeau S, McKenna W, Fitzgerald M, Deharo JC, Alonso C, Walker S, Braunschweig F, Bailleul C, Daubert JC. Long-term benefits of biventricular pacing in congestive heart failure: results from the MUltisite STimulation in cardiomyopathy (MUSTIC) study. J Am Coll Cardiol 2002;40:111-118.

14. Cleland JG, Daubert JC, Erdmann E, Freemantle N, Gras D, Kappenberger L, Tavazzi L; Cardiac Resynchronization-Heart Failure (CARE-HF) Study Investigators. The effect of cardiac resynchronization on morbidity and mortality in heart failure. N Engl J Med 2005;352:1539-1549.

15. St John Sutton MG, Plappert T, Hilpisch KE, Abraham WT, Hayes DL, Chinchoy E. Sustained reverse left ventricular structural remodeling with cardiac resynchronization at one year is a function of etiology: quantitative Doppler echocardiographic evidence from the Multicenter InSync Randomized Clinical Evaluation (MIRACLE). Circulation 2006;113:266-272.

16. Ypenburg C, Lancellotti P, Tops LF, Boersma E, Bleeker GB, Holman ER, Thomas JD, Schalij MJ, Piérard LA, Bax JJ. Mechanism of improvement in mitral regurgitation after cardiac resynchronization therapy. Eur Heart J 2008;29:757-765.

17. Porciani MC, Macioce R, Demarchi G, Chiostri M, Musilli N, Cappelli F, Lilli A, Ricciardi G, Padeletti L. Effects of cardiac resynchronization therapy on the mechanisms underlying functional mitral regurgitation in congestive heart failure. Eur J Echocardiogr 2006;7:31-39.

18. Onishi T, Onishi T, Marek JJ, Ahmed M, Haberman SC, Oyenuga O, Adelstein E, Schwartzman D, Saba S, Gorcsan J. Mechanistic features associated with improvement in mitral regurgitation after cardiac resynchronization therapy and their relation to long-term patient outcome. Circ Hear Fail 2013;6:685-693.

19. Cabrera-Bueno F, García-Pinilla JM, Peña-Hernández J, Jiménez-Navarro $M$, Gómez-Doblas J], Barrera-Cordero A, Alzueta-Rodríguez J, de Teresa-Galván E. Repercussion of functional mitral regurgitation on reverse remodelling in cardiac resynchronization therapy. Europace 2007;9:757-761.

20. Verhaert D, Popović ZB, De S, Puntawangkoon C, Wolski K, Wilkoff BL, Starling RC, Tang WH, Thomas JD, Griffin BP, Grimm RA. Impact of mitral regurgitation on reverse remodeling and outcome in patients undergoing cardiac resynchronization therapy. Circ Cardiovasc Imaging 2012;5:21-26.

21. Boriani G, Gasparini M, Landolina M, Lunati M, Biffi M, Santini M, Padeletti L, Molon G, Botto G, de Santo T, Valsecchi S; InSync/InSync ICD Italian Registry Investigators. Impact of mitral regurgitation on the outcome of patients treated with CRT-D: data from the InSync ICD Italian registry. Pacing Clin Electrophysiol 2012;35:146-154.

22. Vardas PE, Auricchio A, Blanc J-J, Daubert JC, Drexler H, Ector H, Gasparini M, Linde C, Morgado FB, Oto A, Sutton R, Trusz-Gluza M; European Society of Cardiology; European Heart Rhythm Association. Guidelines for cardiac pacing and cardiac resynchronization therapy: the Task Force for Cardiac Pacing and Cardiac Resynchronization Therapy of the European Society of Cardiology. Developed in collaboration with the European Heart Rhythm Association. Eur Heart J 2007;28:2256-2295.

23. Dickstein K, Vardas PE, Auricchio A, Daubert JC, Linde C, McMurray J, Ponikowski P, Priori SG, Sutton R, van Veldhuisen DJ; ESC Committee for Practice Guidelines (CPG). 2010 Focused Update of ESC Guidelines on device therapy in heart failure: an update of the 2008 ESC Guidelines for the diagnosis and treatment of acute and chronic heart failure and the 2007 ESC guidelines for cardiac and resynchronization therapy. Eur Heart J 2010;31:2677-2687.

24. Zoghbi WA, Enriquez-Sarano M, Foster E, Grayburn PA, Kraft CD, Levine RA, Nihoyannopoulos P, Otto CM, Quinones MA, Rakowski H, Stewart WJ, Waggoner A, Weissman NJ; American Society of Echocardiography. Recommendations for evaluation of the severity of native valvular regurgitation with two-dimensional and Doppler echocardiography. J Am Soc Echocardiogr 2003;16:777-802. 
25. Lang RM, Bierig M, Devereux RB, Flachskampf FA, Foster E, Pellikka PA, Picard MH, Roman MJ, Seward J, Shanewise J, Solomon S, Spencer KT, St John Sutton M, Stewart W; American Society of Echocardiography's Nomenclature and Standards Committee; Task Force on Chamber Quantification; American College of Cardiology Echocardiography Committee; American Heart Association; European Association of Echocardiography, European Society of Cardiology. Recommendations for chamber quantification. Eur J Echocardiogr 2006;7: 79-108.

26. Frigerio M, Lunati M, Pasqualucci D, Vargiu S, Foti G, Pedretti S, Vittori C, Cattafi G, Magenta G, Campo C, Bisetti S, Mercuro G. Left ventricular ejection fraction overcrossing $35 \%$ after one year of cardiac resynchronization therapy predicts long term survival and freedom from sudden cardiac death: single center observational experience. Int / Cardiol 2014;172:64-71.

27. Khatib M, Tolosana JM, Trucco E, E, Borràs R, Castel A, Berruezo A, Doltra A, Sitges M, Arbelo E, Matas M, Brugada J, Mont L. EAARN score, a predictive score for mortality in patients receiving cardiac resynchronization therapy based on pre-implantation risk factors. Eur J Heart Fail 2014;16:802-809.

28. Goel SS, Bajaj N, Aggarwal B, Gupta S, Poddar KL, Ige M, Bdair H, Anabtawi A, Rahim S, Whitlow PL, Tuzcu EM, Griffin BP, Stewart WJ, Gillinov M, Blackstone EH, Smedira NG, Oliveira GH, Barzilai B, Menon V, Kapadia SR. Prevalence and outcomes of unoperated patients with severe symptomatic mitral regurgitation and heart failure: comprehensive analysis to determine the potential role of mitraclip for this unmet need. J Am Coll Cardiol 2014;63: $185-186$.

29. Vinereanu D. Mitral regurgitation and cardiac resynchronization therapy. Echocardiography 2008;25:1155-1166.

30. Breithardt OA, Sinha AM, Schwammenthal E, Bidaoui N, Markus KU, Franke A, Stellbrink C. Acute effects of cardiac resynchronization therapy on functional mitral regurgitation in advanced systolic heart failure. J Am Coll Cardiol 2003;41:765-770.

31. Kanzaki H, Bazaz R, Schwartzman D, Dohi K, Sade LE, Gorcsan J. A mechanism for immediate reduction in mitral regurgitation after cardiac resynchronization therapy: insights from mechanical activation strain mapping. J Am Coll Cardiol 2004;44:1619-1625.

32. Di Biase L, Auricchio A, Mohanty P, Bai R, Kautzner J, Pieragnoli P, Regoli F, Sorgente A, Spinucci G, Ricciardi G, Michelucci A, Perrotta L, Faletra F, Mlcochová H, Sedlacek K, Canby R, Sanchez JE, Horton R, Burkhardt JD, Moccetti T, Padeletti L, Natale A. Impact of cardiac resynchronization therapy on the severity of mitral regurgitation. Europace 2011;13:829-838.

33. Van Bommel RJ, Marsan NA, Delgado V, Borleffs CJ, van Rijnsoever EP, Schalij MJ, Bax JJ. Cardiac resynchronization therapy as a therapeutic option in patients with moderate-severe functional mitral regurgitation and high operative risk. Circulation 2011;124:912-919.

34. Upadhyay GA, Chatterjee NA, Kandala J, Friedman DJ, Park MY, Tabtabai SR, Hung J, Singh JP. Assessing mitral regurgitation in the prediction of clinical outcome after cardiac resynchronization therapy. Heart Rhythm 2015;12:1201-1208.

35. Cleland J, Freemantle N, Ghio S, Fruhwald F, Shankar A, Marijanowski M, Verboven $\mathrm{Y}$, Tavazzi L. Predicting the long-term effects of cardiac resynchronization therapy on mortality from baseline variables and the early response. A report from the CARE-HF (Cardiac Resynchronization in Heart Failure) Trial. J Am Coll Cardiol 2008;52:438-445.

36. Díaz-Infante E, Mont L, Leal J, García-Bolao I, Fernández-Lozano I, Hernández-Madrid A, Pérez-Castellano N, Sitges M, Pavón-Jiménez R, Barba J, Cavero MA, Moya JL, Pérez-Isla L, Brugada J; SCARS Investigators. Predictors of lack of response to resynchronization therapy. Am J Cardiol 2005;95:1436-1440. 